
\title{
R Reserach Square \\ Opto-Electronic Properties of Epoxy/Silicone Blend Based Thin Films
}

\section{Younes Ziat}

Universite Sultan Moulay Slimane de Beni-Mellal

Hamza Belkhanchi

Universite Sultan Moulay Slimane de Beni-Mellal

Maryama Hammi

UM5A: Universite Mohammed V de Rabat

Charaf Laghlimi ( $\nabla$ charaf.cac.fbs@gmail.com )

Facultes des sciences technique hocaima

A Moutcine

Universite Sultan Moulay Slimane de Beni-Mellal

\section{Research Article}

Keywords: Epoxy/Silicon N-CNTs, Optical properties, N-CNTs, sol-gel method, UV-Visible, optical pseudogap, Urbach energy

Posted Date: March 22nd, 2021

DOl: https://doi.org/10.21203/rs.3.rs-303344/v1

License: (1) This work is licensed under a Creative Commons Attribution 4.0 International License.

Read Full License 


\title{
Opto-electronic properties of Epoxy/Silicone blend based thin films
}

\author{
Y. Ziat ${ }^{1}$, H. Belkhanchi ${ }^{1}$, M. Hammi ${ }^{2}$, C. Laghlimi ${ }^{3}$, A. Moutcine ${ }^{4}$ \\ ${ }^{1}$ Laboratory of Engineering and Applied Technologies, Higher School of Technology, Sultan \\ Moulay Slimane University, Beni Mellal, Morocco \\ ${ }^{2}$ Laboratory of Materials, Nanotechnologies and Environment, Department of Chemistry, \\ Faculty of Sciences, University of Mohammed V, Rabat, Morocco \\ ${ }^{3}$ Applied Chemistry Team, Faculty of Sciences and Techniques of Al Hoceima, Abdelmalek \\ Essaadi University, Al Hoceima, Morocco \\ ${ }^{4}$ Molecular Electrochemistry and Inorganic Materials Team, Beni Mellal, Faculty of Science \\ and Technology, Sultan Moulay Slimane University, Morocco
}

\begin{abstract}
:
Recently, the rise of two dimensional amorphous nanostructured thin films have ignited a big interest because of their intriguingly isotropic structural and physical properties leading to potential applications in the nano-optoelectronics. However, according to literature, most of optoelectronic properties are investigated on chalcogenides related heterostructures. This has motivated the present work aiming to provide a new platform for the fabrication, examination of the properties and the applications of 2D nanostructured thin films based on epoxy/silicone blend. Thin films of Epoxy/Silicone loaded with nitrogen doped carbon nanotubes (N-CNTs) were prepared by sol-gel method and deposited on Indium Tin Oxide (ITO) glass substrates at room temperature. Further examination of optical properties aimed the investigation of optical pseudo-gap and Urbach energy and enabled the determination of processed films thickness based on Manifacier and Swanepol method. The results indicated that the unloaded thin films have a direct optical transition with a value of $3.61 \mathrm{eV}$ followed by noticeable shift towards narrowing gaps depending on the loading rate. Urbach's energy is $0.19 \mathrm{eV}$ for the unloaded thin films, and varies from 0.43 to $1.33 \mathrm{eV}$ for the loaded thin films with increasing the rate of NCNTs. It is inversely variable with the optical pseudo-gap. Finally, Epoxy/Silicone loaded with N-CNTs nanocomposites films can be developed as active layers with specific optical characteristics, giving the possibility to be used in electro-optical applications.
\end{abstract}

Keywords: Epoxy/Silicon N-CNTs, Optical properties, N-CNTs, sol-gel method, UV-Visible, optical pseudo-gap, Urbach energy 


\section{INTRODUCTION}

To some extent, the performance of electronic devices in photovoltaic applications is tightly depending on the energetic alignment of the valence and conduction band edges at interfaces. The electrostatic and well as van der Waals stacking interactions are the key parameters controlling interfacial electronic effects and resulting in a better dispersion of the fillers within the composites. Photovoltaic solar energy is an electrical energy produced from solar radiation by photovoltaic solar cells [1]. This kind of energy is the smartest way to produce electricity, and it has many advantages, such as: direct generation of electricity from sunlight [2-3]. It is a renewable source and clean [4-11], as well as friendly to the environment $[5,8,11-14]$. The Photovoltaic energy is useful in different applications and devices [15-21].

The prices of the solar cells based on $(\mathrm{Si})$ have declined so speedily that panel expenses now make up $<30 \%$ of the costs of a fully installed "solar-electricity-system" [22]. Since of their fragility, Si thin sheets cannot be treated on their own, but they must be mechanically supported. The researchers proposed to scale thick substrates by adding different materials such as: Aluminum, silver, nickel and epoxy [23-26]. They are generally composed of a mixture of inorganic particles embedded in a polymer matrix.

In the recent years, the research interest in the development of a new material of polymerinorganic nanocomposites with improved properties has been very high [27-33], and most research has been directed towards the use of materials in the form of thin films. The nanocomposites allow to improve mechanical, electrical, optical, optoelectronic and magnetic properties. For this reason, many studies have shown that hybrid nanocomposites are used in optoelectronic or optical applications requiring high visible transparency and shielding against ultra-visible [34-40].

Today, energetic deposition means are widely used for the manufacture of thin film optical components [41]. These processes allow the fabrication of thin film materials with excellent repeatability, whose optical properties are very close to those of the solid material, thus opening doors to higher performance treatments that are insensitive to the constraints of the external environment. This was only possible with the technology developments in thin films deposition using several physical deposition techniques such as reactive sputtering [42], electron beam evaporation [43] and arc deposition [44-45]. In particular, the sol-gel method has emerged as one of the most promising processes, as it is economical and efficient in the production of thin 
films [46] as well as transparent and homogeneous films which are suitable for a variety of substrates. These different properties make the sol-gel process a method of choice for the production of either amorphous or crystalline materials.

In this paper, we report a simple and economical method for elaborating thin films of epoxy/ silicone blend loaded by Nitrogen-doped carbon nanotubes (N-CNTs). The nanocomposites are thin films having interesting optical properties. These films may offer potential new opportunities for photovoltaic applications caused by their specific chemical and electrical properties performant [47-50].

\section{EXPERIMENTAL WORK}

\subsection{Material and Methods}

The elaborated matrix contains Epoxy which is colorless viscous liquid of $99.9 \%$ purity, supplied along with the hardner from Toronto Research Chemicals and silicone gel from Keol having high purity level (>99\%).

The fillers are the nitrogen-doped carbon nanotubes (N-CNTs) which were prepared using physical vapor deposition according to explained protocol in our previous paper [51].

Substrate cleaning is a very important step that takes place in a clean room, as this step determines the adhesion and homogeneity of the deposited layers. The substrates must be free of grease, dust and scratches. The substrates chosen for our study are blades Indium Tin Oxide (ITO). he procedure for cleaning the substrates is as follows:

1) Brushing with detergent, rinsing with de-ionized water,

2) Ultrasonic cleaning for ten minutes in a beaker filled with detergent,

3) Rinse with de-ionized water,

4) Ultrasonic cleaning again, but this time in a beaker filled with water deionized, for seven minutes,

5) Steps 3 and 4 are performed three times,

6) Last rinsing with deionized water,

7) drying at $150{ }^{\circ} \mathrm{C}$ for 15 minutes.

First, epoxy and Silicone were mixed in a $50 \mathrm{ml}$ beaker with the weight percentage of epoxy is always kept higher than that of Silicone and after a strong stirring the hardener is added to avoid 
anisotropy and in order to keep homogeneity. The neat matrix contains $75 w t \%$ of epoxy, 10 $w t \%$ of Silicone and $15 w t \%$ of hardener. Afterward, the N-CNTs were added with weight percent $(0.00 ; 0.07 ; 0.1$ and $0.2 \%$ of $\mathrm{N}-\mathrm{CNTs})$ in order to obtain homogeneous nanocomposites with consideration that they are formulated using the same process.

The resulting mixture was deposited on the ITO glass substrate at room temperature. The prepared films were thermally cured at 103 for 1 hour then at $115^{\circ} \mathrm{C}$ for $30 \mathrm{~min}$ in the oven to obtain the Epoxy/silicone N-CNT films.

\subsection{Technical Characterizations}

After preparing the thin films of Epoxy/Silicone N-CNT, microstructural and optical characterization were carried out, using, respectively, the scanning electron microscopy and UV-Visible technique which is based on the property of material and its ability to absorb certain wavelengths of the UV-visible domain. This method determines the transmission $\mathrm{T}(\%)$ of a material for a given wavelength $\lambda(\mathrm{nm})$ that has been judiciously chosen. The optical transmission spectrum for the elaborated thin films were registered using UV-Visible spectrophotometer (Jasco V-530) over the wavelength range of 300-800 $\mathrm{nm}$. The microstructure of the processed composite thin films were examined through SEM micrographs which were picked up for epoxy/silicone blend loaded with $0.2 \mathrm{wt} \% \mathrm{~N}-\mathrm{CNT}$ s using FEI Quanta FEG 450 scanning electronic microscope (SEM).

\section{RESULTS AND DISCUSSION}

\subsection{Optical Properties}

Figure 1 shows the transmittance $(\mathrm{T})$ spectrum of the thin films of Epoxy/Silicone N-CNT as a function of wavelength at room temperature in the spectral range of $300-800 \mathrm{~nm}$. The transmittance spectrum has a high transmittance of up to $88 \%$ in the visible range for Neat Epoxy/Silicone blend, indicating a highly transparent material, it is pointed out that transmittance in the overall wavelength range is considerably reduced with the increased fillers content ranging from 0.07 to $0.2 w t \% \mathrm{~N}-\mathrm{CNT}$. 


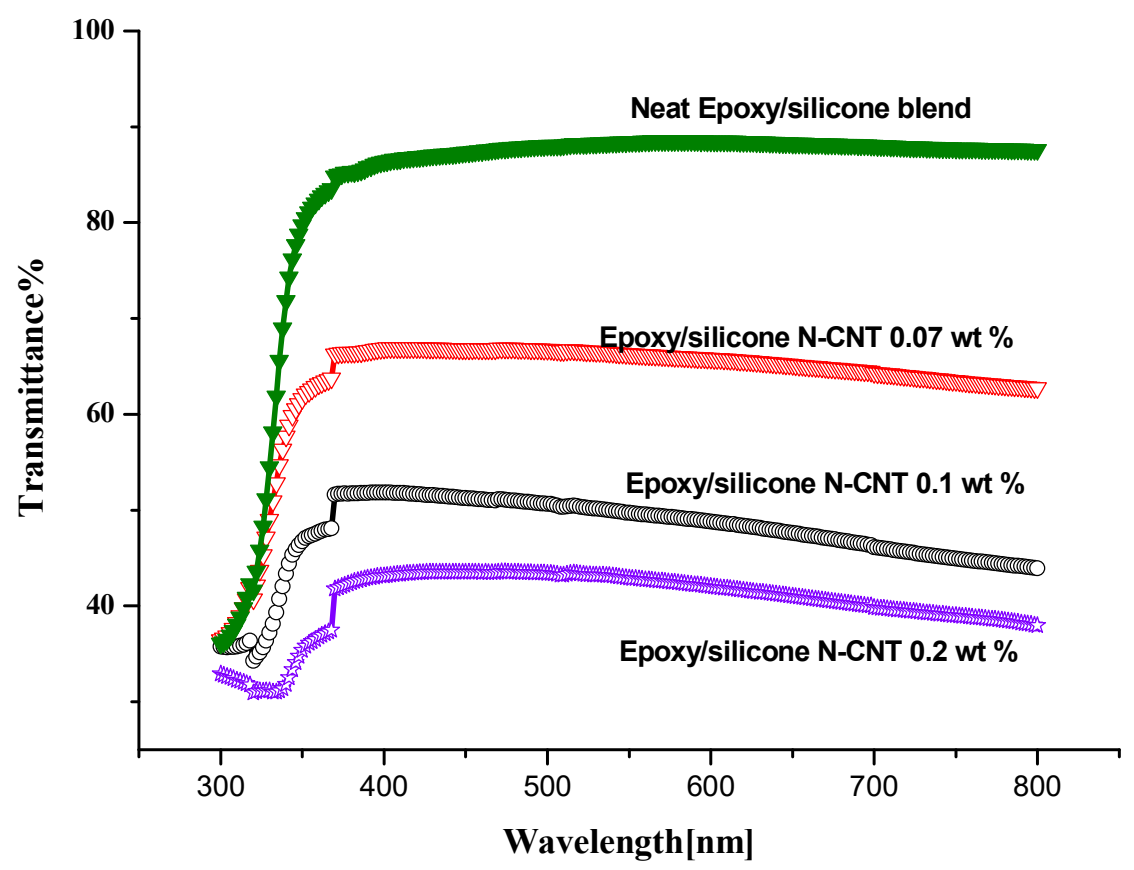

Figure. 1: plots of Epoxy/silicone films transmittance as a function of wavelength for different N-CNTs loading rates

This drastic reduction is caused by significant absorption increasing with the quantity of the NCNTs fillers, this effect is significant in the optimization of the fabrication of the optoelectronic devices. The spectrophotometer allows recording the optical transmission of the layers as a function of wavelength and allows determining the value of the energy of the optical pseudogap $\left(\mathrm{E}_{\mathrm{g}}\right)$ of the layer (characteristic of a semiconductor), the refractive index of the films and their thicknesses. For this aim, we will use the following formulas given by the method of Manifacier and Swanepol [52-53]. The thickness of the nanostructures is determined from the following equation:

$$
\mathrm{d}=\left(\frac{\lambda_{1} \lambda_{2}}{2\left(\lambda_{1} \mathrm{n}_{2}-\lambda_{2} \mathrm{n}_{1}\right)}\right)
$$

With $n_{1}$ and $n_{2}$ are the refractive indices at two adjacent maxima (or minima) at $\lambda_{1}$ and $\lambda_{2}$.

The average values of thickness $d$ of the studied thin films determined by this equation is about $700 \mathrm{~nm}$.

The refractive index in the spectral region of the high, low and medium absorption zones can be calculated, it follows that the refractive index is given by the expression:

$$
\mathrm{n}_{1}=\left[\mathrm{N}_{1}+\left(\mathrm{N}_{1}^{2}-\mathrm{S}^{2}\right)^{1 / 2}\right]^{1 / 2} \quad \mathrm{n}_{2}=\left[\mathrm{N}_{2}+\left(\mathrm{N}_{2}^{2}-\mathrm{S}^{2}\right)^{1 / 2}\right]^{1 / 2}
$$


In addition, the Swanepoel coefficient (N) in the transparent spectral region can be calculated by the following expression:

$$
\mathrm{N}_{1}=2 \mathrm{~S}\left(\frac{\mathrm{T}_{\max 1}-\mathrm{T}_{\min }}{\mathrm{T}_{\max 1} \times \mathrm{T}_{\min }}\right)+\left(\frac{\mathrm{S}^{2}+1}{2}\right) \quad \mathrm{N}_{2}=2 \mathrm{~S}\left(\frac{\mathrm{T}_{\max 2}-\mathrm{T}_{\min }}{\mathrm{T}_{\max 1} \times \mathrm{T}_{\min }}\right)+\left(\frac{\mathrm{S}^{2}+1}{2}\right)
$$

Where $\mathrm{S}$ is the refractive index of the glass, $\mathrm{T}_{\max }$ and $\mathrm{T}_{\min }$ represent the maximum and minimum values for the transmission curve.

The absorption $\alpha$ of the of the Epoxy/Silicone N-CNT nanocomposite is linked to transmittance through Bouguer-Lambert-Beer relation [54]:

$$
\mathrm{T}=\exp (-\alpha \mathrm{d})
$$

If transmittance $\mathrm{T}$ is expressed in (\%), the absorption coefficient is shown by:

$$
\alpha=\frac{1}{d} \ln \left(\frac{100}{T}\right)
$$

We can from the transmittance spectra $(\mathrm{T})$ calculate the optical gap value of semiconductors from the Tauc formula $\left(\mathrm{E}_{\mathrm{g}}(\mathrm{eV})\right)$ defined by the following equation using [55-59]:

$$
(\alpha h v)=B\left(h v-E_{g}\right)^{n}
$$

The relation can be rewritten in a logarithmic form such as:

$$
\ln (\alpha h v)=\ln B+n \ln \left(h v-E_{g}\right)
$$

Where $\alpha$ is the absorption coefficient, $v$ is the absorption frequency, $\mathrm{B}$ is constant, $\mathrm{h}$ is Planck's constant and $\mathrm{n}$ is dependent on the type of optical transition, The constant $\mathrm{n}$ depends on the nature of the optical gap, it is $\frac{1}{2}$ for a direct optical gap and 2 for an indirect optical gap.

Note that, the interband transitions are accompanied by a change of electronic dynamics. Because the laws of energy and momentum conservation must be satisfied, the indirect electronic band-to-band transitions are phonon-assisted, phonons must be involved in the electronic interband transition to provide the necessary momentum. Their energetic contribution is negligible if for instance the exponent takes the value of $n=2$ [60].

To determine whether the electronic transition that has occurred in the samples studied is direct or indirect, the optical gap $\mathrm{E}_{\mathrm{g}}$ must first be determined using equation 6 to plot $\alpha \mathrm{h} v$ versus $\mathrm{h} v$, the value of the optical gap is obtained by extrapolating the linear part of the curve, at the 
intersection of this line with the $\mathrm{x}$-axis given in Table 1 , then the photon energy $\ln \left(\mathrm{h} v-\mathrm{Eg}_{\mathrm{g}}\right)$ is plotted versus $\ln (\alpha h v)$ which has been fitted with equation 7 in the linear region of the curve, using the average-squares method, where $\mathrm{E}_{\mathrm{g}}, \mathrm{n}$ and $\mathrm{B}$ are fitted parameters, this process can show that the type of optical transition of the pure epoxy/silicone mixture is direct with the power factor $n=0.51$ and the same result was obtained for the Epoxy/Silicone N-CNT $w \%$ loaded.

Table 1: The optical parameters; optical pseudo- gap $E_{g}$, power factor (n), Tauc verified $E_{g}$ and Urbach energy $E_{u}$ of the studied composite.

\begin{tabular}{cccccc}
\hline \multicolumn{7}{c}{ Parameters obtained by : } & $(\alpha h v)=B\left(h v-E_{g}\right)^{n}$ & & \\
Composite & $\mathrm{E}_{\mathrm{g}}(\mathrm{eV})$ & Factor $(\mathrm{n})$ & Slope $\left(\mathrm{eV} . \mathrm{cm}^{-1}\right)^{1 / n}$ & $\begin{array}{c}\text { Tauc Verified } \\
\mathrm{E}_{\mathrm{g}}(\mathrm{eV})\end{array}$ & Urbach energy $\mathrm{E}_{\mathrm{U}}(\mathrm{eV})$ \\
\cline { 1 - 4 } Neat Epoxy/silicone blend & 3.61 & 0.51 & $4.2010^{8}$ & 3.6 & 0.19 \\
\hline Epoxy/silicone N-CNT 0.07 wt \% & 3.55 & 0.50 & $3.1810^{8}$ & 3.38 & 0.43 \\
\hline Epoxy/silicone N-CNT 0.1 wt \% & 3.42 & 0.54 & $3.2010^{8}$ & 3.3 & 0.61 \\
\hline Epoxy/silicone N-CNT 0.2 wt \% & 3.19 & 0.51 & $2.9810^{8}$ & 3.1 & 1.33 \\
\hline
\end{tabular}

To verify the validity of the method used, we plotted of $(\alpha h v)^{2}$ versus $h v$ as shown in Figure 2 according to the Tauc model [61], gives the value of the direct optical gap. The extrapolation of the linear part of the absorption edge $(\alpha h v)^{2}$ gives the band gap energy. The use of the power factor $\mathrm{n}$ obtained gives a good agreement between the optical gap bands and the Tauc slopes, almost the same optical gap Eg is found (Table 1), so the correlation between experience and theory is compatible. 


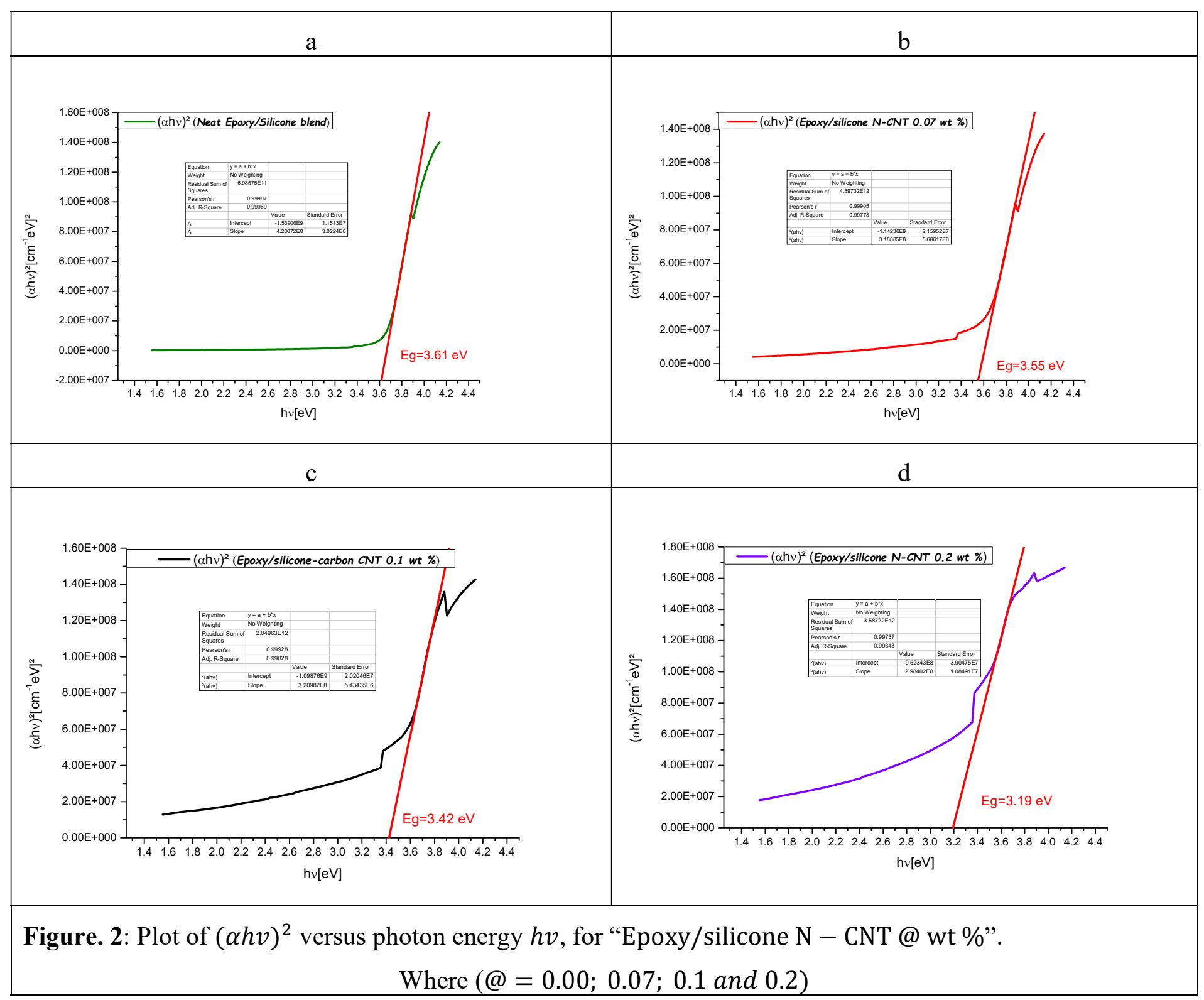


Obviously, the optical pseudo-gap obtained is high for Neat Epoxy (is of 3,6 eV), because it is optically transparent and this means that no absorption is possible in the visible, they cannot be excited without being loaded with another element to decrease $\mathrm{E}_{\mathrm{g}}$, so we load with N-CNT and we see that there is a diminution in $\mathrm{E}_{\mathrm{g}}$ in 3,6 to $3,1 \mathrm{eV}$ (Table 1), this decrease of the optical pseudo-gap with the loading rate is essentially due to the distortions caused in the network following the introduction of impurity (loading) and the increase in the concentration of free electrons, this characteristic would seem to be related to the increase in the number of free carriers with increasing the concentration of nanocomposite loaded in $0.07,0.1$ and $0.2 \mathrm{wt} \% \mathrm{~N}-$ CNT (Table 1 and Fig.3).

So the system is progressively becoming more conductor with addition of N-CNT, this seems to change slightly the structure of the electronic bands of the Neat Epoxy. In addition, the variation of optical pseudo-gap with increasing N-CNT loaded concentration can also be correlated with surface roughness and film density.

When variations in interatomic distance, length or angle of bonding are produced in the material, a so-called "disorder" occurs, in this case, the strip edges described in the case of crystalline networks and delimited by valence energy Ev and conduction energy Ec can disappear (Fig.4), so-called localized states formed in band tails at the borders of the optical pseudo-gap in the valence band and the conduction band are observed.

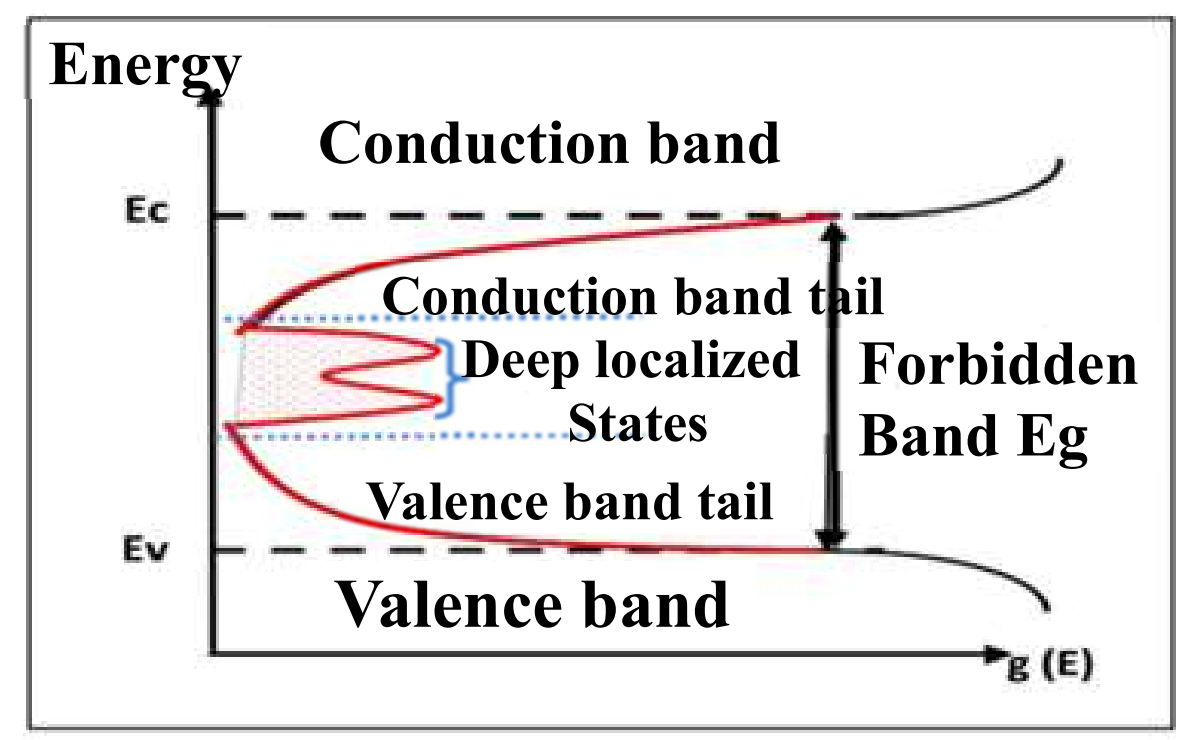

Figure 3. Pseudo-gap of amorphous semiconductors

The forbidden gap is referred as the pseudo gap energy for amorphous semiconductors as in the case of our composites, we note Eg. The generation phenomena can only happen if the light 
energy is larger than the band gap energy of semiconductor. For a wide-band-gap semiconductor, this band gap energy is correspondent to the visible or ultraviolet spectrum excitations. As consequence, the increase of charge carriers' concentrations in the conduction band may be slight which maintains such materials type is quite electrical insulator. The electrical conductivity of amorphous semiconductors can be tuned in several ways. The basic idea is to create free charge carriers (electrons or holes) in wide-band-gap semiconductor through appropriate fillers. This can create extrinsic impurities in the amorphous insulating materials which play a critical role for improving their electrical conductivity.

When the disorder becomes too great, with the appearance of dangling links or impurities in the material, one then recalls the notion of Urbach parameter $E_{U}$ that corresponds to the transition between the extended states of the valence band and the localized states [62]. This phenomenon is exemplified with the absorption coefficient $(\alpha)$ as a function of photon energy near the edge of the band, exhibiting an exponential tail as shown in Figure 5 according to Urbach's law, the expression of the absorption coefficient is of the form [63]:

$$
\alpha=\alpha_{0} \exp \left(\frac{\mathrm{h} v}{E_{U}}\right)
$$

$\mathrm{h}$ is the Planck's constant, $\alpha_{0}$ is a constant, $v$ is the frequency of absorption and Urbach energy $E_{U}$. To determine the disorder (Urbach energy) of thin films, we plot the logarithm of $\alpha$ versus of hv:

$$
\ln (\alpha)=\alpha_{0}+\frac{\mathrm{h} v}{E_{U}}
$$

Elsewhere, have studied the effect of disorder processes and phase transitions on the Urbach absorption edge. It is shown that it is possible to obtain the information on the dynamics of the electronic excitations of condensed matter by urbach rule. Thus, Urbach's rule makes it fairly easy to find the degree of the location of the states in the network and to determine the effect of network disorder on the location of the excitement.[64]. 


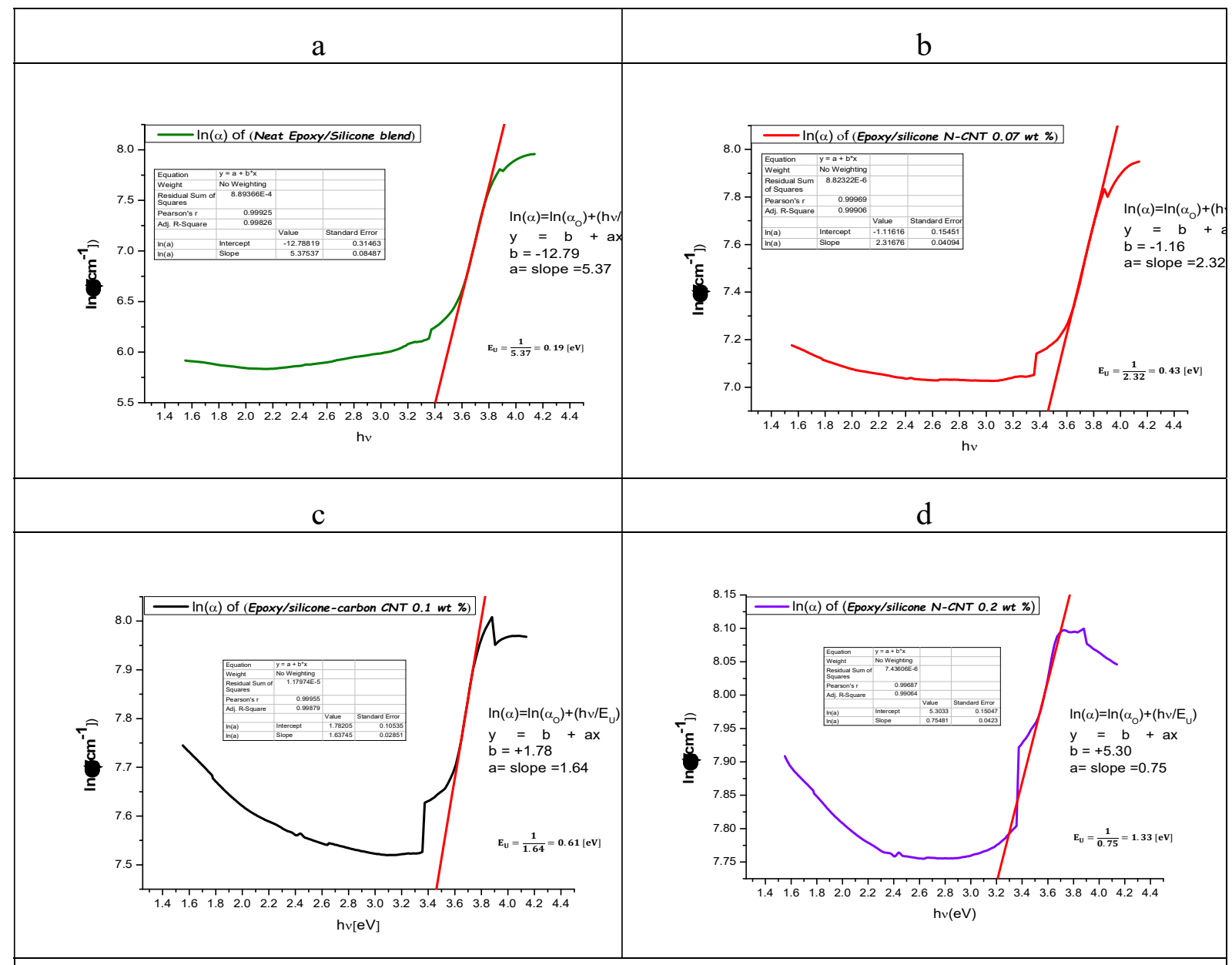

Figure. 5: Determination of Urbach energy $\mathbf{E}_{\mathbf{U}}$ by the plot of $\ln (\alpha)$ versus photon energy $h v$ for "Epoxy/silicone N - CNT @ wt \%”. Where (@=0.00; 0.07; 0.1 and 0.2)

Figure 4 shows the plot of $\ln (\alpha)$ versus energy h $v$ for a series of thin films of neat epoxy (Fig 4(a)) and Epoxy/silicone loaded at different concentrations, Fig 4(b, c and d). Therefore, Urbach energy is determined by the reciprocal slope of the adjusted experimental linear behavior, the results of the study are shown in Table 1. The evolution of the Urbach energy versus the $w t \% \mathrm{~N}-\mathrm{CNT}$ loaded is presented in Figure5, this figure shows that the Urbach energy values were higher in loaded Epoxy/silicone than in the Neat, and that the highest value was obtained in the most filled loaded Epoxy/silicon.

The increase in tail width can be explained by the creation of disorder and imperfections in the nanocomposite lattice by addition of N-CNT.

The Urbach energy also depends on the optical energy band Eg. The Urbach energy increases from 0.19 to $1.33 \mathrm{eV}$ while $\mathrm{Eg}$ decreases from 3.6 to $3.1 \mathrm{eV}$ as the amount of N-CNT increases (Table 1 and Fig.6). 


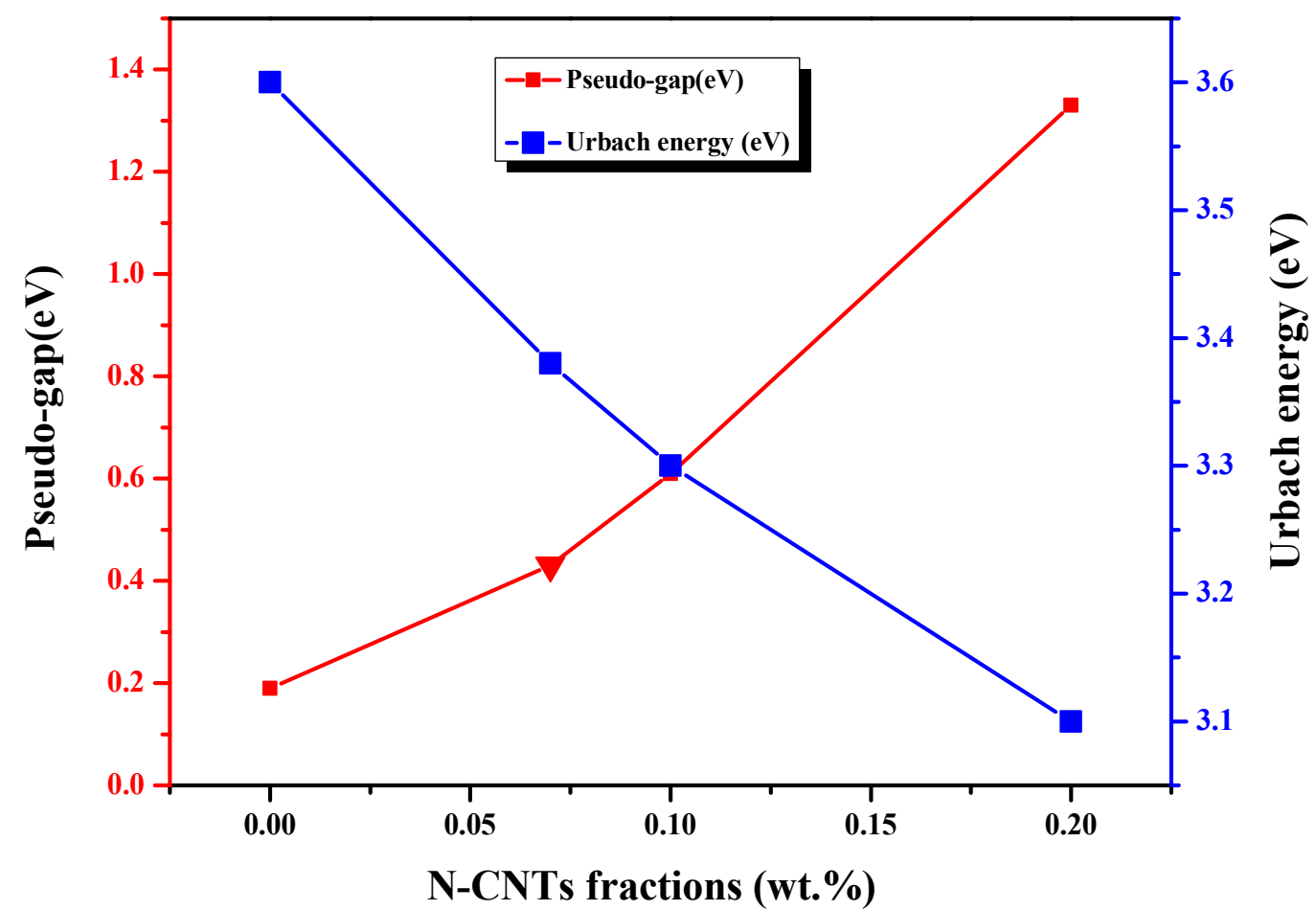

Figure 6: Variation of optical gap and Urbach energy of Epoxy/silicone composite films versus $w t \% \mathrm{~N}-\mathrm{CNT}$

The variation found in $E_{U}$, indicates that the N-CNT addition creates a certain disorder, which leads to the structural characterization of the deposits, and the defects are deduced from the Urbach energy exponential absorption tail caused by fluctuations within the matrix optical pseudo-gap. Moreover, it can be seen that the increase in Urbach's energy opposes the decreasing behaviour of the optical optical pseudo-gaps with increasing $w \% \mathrm{~N}-\mathrm{CNT}$ as shown in Figure 5, so the Urbach's energy is consistent with the determined values of the optical pseudo-gap energy. There is also a significant change in slope above the percolation threshold, in $\mathrm{w} \% 0.07$ of Epoxy/Silicone composite film for optical pseudo-gap and Urbach energy. Indeed, above the percolation threshold the electron carrier concentration exceeds the density of the conduction band states, the composites become semi-conducting, and their number of carrier's increases significantly. Therefore, the optical pseudo-gap must decrease significantly, and the results are in accordance with the theory of Burstein-Moss [65-66].

\section{$\underline{\text { 3.2. Microstructural insight }}$}




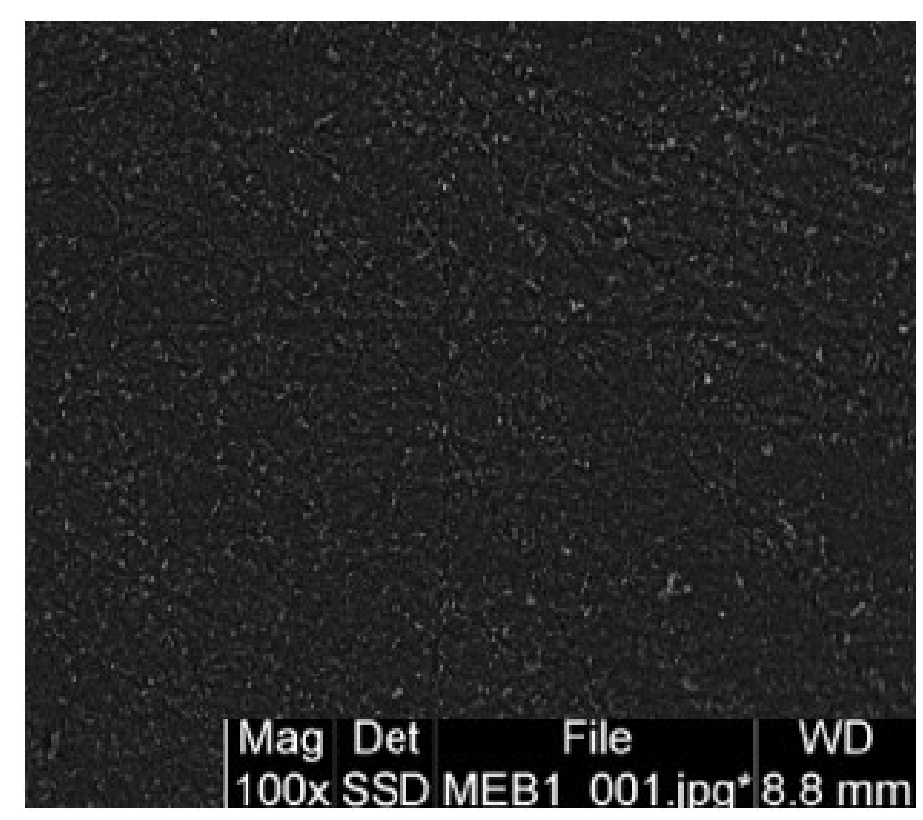

Figure 6: SEM observed the morphology of the thin film surface

The cured composites exhibited a very dense and relatively smooth surface. The SEM photographs revealed that N-CNTs particles were found to be uniformly dispersed throughout the epoxy/silicone blend matrix. This result revealed that there is a good miscibility between the phases.in a good agreement with elsewhere findings [67].

\section{CONCLUSION}

The optical properties were studied from UV-Visible spectroscopy to examine the transmission spectrum, Optical pseudo-gap, Tauc verified pseudo-gap and Urbach energy, based on the envelope method proposed by Swanepoel.

The study shows that the films obtained show a high transmittance for the unloaded thin films of Neat Epoxy/Silicone blend about $88 \%$ and an average transmittance for the loaded thin film of Epoxy/Silicone N-CNT about 42 to $67 \%$ in the visible range and opaque in the UV range.

The results indicate that the film has a direct optical transition with an optical pseudo-gap of $3.61 \mathrm{eV}$ for unloaded thin films, and 3.55 to $3.19 \mathrm{eV}$ for loaded thin films depending on the loading rate. The optical pseudo-gap was appropriately adapted to the direct transition model proposed by Tauc, its value was $3.6 \mathrm{eV}$ for unloaded thin films, and from 3.38 to $3.1 \mathrm{eV}$ for loaded thin films, then determining Urbach's energy which is inversely tended with Eg which varies from $0.19 \mathrm{eV}$ for unloaded thin films, and from 0.43 to $1.33 \mathrm{eV}$ for loaded thin films. The obtained results show the success of the method Sol-Gel to elaborate Epoxy/Silicone 
loaded with N-CNT films with properties adapted to the physical applications. These results also show that it was possible to modify the loaded Epoxy films by inserting a loading. In the near future, this gives hope for applications such like waveguides, electrochemistry, optical fibers, and solar cells.

\section{References}

[1] P. G. V. Sampaio, M. O. A. González, (2017) "Photovoltaic solar energy: Conceptual framework", Renewable and Sustainable Energy Reviews, vol. 74, pp. 590-601.

[2] W. Hoffmann, (2006) "PV solar electricity industry: market growth and perspective", Sol Energy Mater Sol Cells, vol. 90, pp. 3285-3311.

[3] P. Kui-Qing, L. Shuit-Tong, (2011) "Silicon nanowires for photovoltaic solar energy conversion”, Advanced Materials, vol. 23, pp. 198-215.

[4] J. L. Silveira, C. E. Tuna, W. de Q. Lamas (2013), "The need of subsidy for the implementation of photovoltaic solar energy as supporting of decentralized electrical power generation in Brazil”, Renewable and Sustainable Energy Reviews, vol. 20, pp. 133-141.

[5] J. Peng, L. Lu, H. Yang, (2013) "Review on life cycle assessment of energy payback and greenhouse gas emission of solar photovoltaic systems", Renewable and Sustainable Energy Reviews, vol. 19, pp. 255-274.

[6] T. Bhattacharya, A. K. Chakraborty, K. Pal, (2014) "Effects of ambient temperature and wind speed on performance of monocrystalline solar photovoltaic module in Tripura, India', Journal of Solar Energy, vol. 2014, pp. 1-5

[7] H. Kim, E. Park, S. J. Kwon, J. Y. Ohm, H. J. Chang, (2014) “An integrated adoption model of solar energy technologies in South Korea', Renewable Energy, vol. 66, pp. 523-531.

[8] M. Hosenuzzaman, N.A. Rahim, J. Selvaraj, M. Hasanuzzaman, A. B. M. A. Malek, A. Nahar, (2015) "Global prospects, progress, policies, and environmental impact of solar photovoltaic power generation", Renewable and Sustainable Energy Reviews, vol. 41, pp. 284297.

[9] Z. Lan, J. Li, (2014) "Photovoltaic Technology and Electricity Saving Strategies for FixedVelocity-Measuring System”, TELKOMNIKA Indones J Electr Eng, vol. 12, pp. 4419-26. 
[10] G. Liu, (2014) "Sustainable feasibility of solar photovoltaic powered street lighting systems", International Journal of Electrical Power \& Energy Systems, vol. 56, pp. 168-174.

[11] N.S. Lewis, (2015) “Introduction: Solar Energy Conversion”, Chemical Reviews, vol. 115, pp. 12631-12632.

[12] L. El Chaar, L.A. lamont, N. El Zein, (2011) ''Review of photovoltaic technologies', Renewable and Sustainable Energy Reviews, vol. 15, pp. 2165-2175.

[13] V.V. Tyagi, N.A.A. Rahim, N. A. Rahim, N. A, A. Jeyraj / L. Selvaraj, (2013) "Progress in solar PV technology: Research and achievement", Renewable and Sustainable Energy Reviews, vol. 20, pp. 443-461.

[14] J. Mundo-Hernández, B. de Celis Alonso, J. Hernández-Álvarez, B. de Celis-Carrillo, (2014) "An overview of solar photovoltaic energy in Mexico and Germany", Renewable and Sustainable Energy Reviews, vol. 31, pp. 639-649

[15] B. Parida, S. Iniyan, R. Goic, (2011) “A review of solar photovoltaic technologies", Renewable and Sustainable Energy Reviews, vol. 15, pp. 1625-1636.

[16] R.W. Miles, K.M. Hynes, I. Forbes, (2005) "Photovoltaic solar cells: An overview of state-of-the-art cell development and environmental issues", Progress in Crystal Growth and Characterization of Materials, vol. 51, pp. 1-42.

[17] R.W. Miles, (2006) "Photovoltaic solar cells: Choice of materials and production methods" Vacuum, vol. 80, pp. 1090-1097.

[18] R.W. Miles, G. Zoppi, I. Forbes, (2007) “Inorganic photovoltaic cells”, Materials Today, vol. 10 , pp. $20-27$.

[19] A. Zahedi, (2006) "Solar photovoltaic (PV) energy; latest developments in the building integrated and hybrid PV systems", Renewable Energy, vol. 31, pp. 711-718.

[20] S. Mekhilef, R. Saidur, A. Safari, (2011) “A review on solar energy use in industries", Renewable and Sustainable Energy Reviews, vol. 15, pp. 1777-1790.

[21] V. Devabhaktuni, M. Alam, S. Shekara Sreenadh Reddy Depuru, R.C. Green, D. Nims, C. Near, (2013) "Solar energy: Trends and enabling technologies", Renewable and Sustainable Energy Reviews, vol. 19, pp. 555-564. 
[22] N.S. Lewis, (2016) ' 'Research opportunities to advance solar energy utilization', Science, vol. 351, aad1920.

[23] R. Niepelt, J. Hensen, A. Knorr, V. Steckenreiter, S. Kajari-Schroder, R. Brendel, (2014) in 4th International Conference on Crystalline Silicon Photovoltaics.

[24] R. Ramadan,M. Manso-Silván, R.J. Martín-Palma, (2020) "Hybrid porous silicon/silver nanostructures for the development of enhanced photovoltaic devices", Journal of Materials Science. vol. 55, pp. 5458-5470.

[25] S. W. Bedell, D. Shahrjerdi, B. Hekmatshoartabari, K. Fogel, P. Lauro, N. Sosa, D. Sadana, (2011), in 37th IEEE Photovoltaic Specialist Conference.

[26] R. Martini, M. Gonzalez, F. Dross, A. Masolin, J. Vaes, D. Frederickx, J. Poortmans, (2012) “Epoxy-Induced Spalling of Silicon’, Energy Procedia, vol. 27, pp. 567-572.

[27] Wang. M. S, Pinnavaia. T. J, (1994) '’Clay-Polymer Nanocomposites Formed from Acidic Derivatives of Montmorillonite and an Epoxy Resin. Chemistry of Materials', Chem. Mater, vol. 6, pp. 468-474.

[28] E. P. Giannelis, (1996) "Polymer Layered Silicate Nanocomposites", Advanced Materials, vol.8, pp. 29-35.

[29] J. Wu, P.T. Mather, (2009) "POSS Polymers: Physical Properties and Biomaterials Applications", Polymer Reviews, vol. 49, pp. 25-63.

[30] Strachota. A, Whelan. P, Kriz. J, Brus. J, Urbanova. M, Slouf. M, Matejka. L, (2007) 'Formation of nanostructured epoxy networks containing polyhedral oligomeric silsesquioxane (POSS) blocks"',Polymer, vol. 48, pp. 3041-3058.

[31] Q. Li, L. Chen, M. R. Gadinski, S. Zhang, G. Zhang, H. Li, A. Haque, L. Q. Chen, T. Jackson, Q. Wang, (2015) 'Flexible high-temperature dielectric materials from polymer nanocomposites", Nature, vol. 523, pp. 576-579.

[32] C. Sanchez, B. Lebeau, (2001) ''Design and Properties of Hybrid Organic-Inorganic Nanocomposites for Photonics”, MRS Bulletin, vol. 26, pp. 377-387.

[33] R. Mangal, S. Srivastava, L. A. Archer, (2015) 'Phase stability and dynamics of entangled polymer-nanoparticle composites", Nature Communications, vol. 6, p. 7198. 
[34] A. Thabet, Y.A. Mobarak, M. Bakry, (2011) 'A review of nano-fillers effects on industrial polymers and their characteristics", Engineering Sciences, vol 39, pp 377-403.

[35] L. Shanghua, M.L. Meng, S.T. Muhammet, K.K. Do, M. Mamoun, (2010) 'Nanocomposites of polymer and inorganic nanoparticles for optical and magnetic applications', Nano Reviews, vol 1, p 5214.

[36] S. Kango, S. Kalia, A. Celli, J. Njuguna, Y. Habibi, and R. Kumar, (2013) "Surface modification of inorganic nanoparticles for development of organic-inorganic nanocomposites - A review", Progress in Polymer Science, vol. 38, pp. 1232-1261.

[37] X.Y. Huang, H.R. Heulings, IV, V. Le, J. Le, (2001) 'Inorganic-organic hybrid composites containing MQ (II-VI) slabs: A new class of nanostructures with strong quantum confinement and periodic arrangement", Chemistry of Materials, vol.13, pp. 3754-3759.

[38] W. Caseri, (2008) 'Inorganic nanoparticles as optically effective additives for polymers', Chemical Engineering Communications, vol. 196, pp. 549-572.

[39] H. Althues, J. Henle, S. Kaskel, (2007) ' Functional inorganic nanofillers for transparent polymers', Chemical Society Reviews, vol. 36, pp. 1454-1465.

[40] P.M. Ajayan, L.S. Schadler, P.B. Braun, (2003) 'Nanocomposite Science and Technology", Wiley-VCH, Weinheim, Germany.

[41] H. A. Macleod, (2013) "Recent developments in deposition techniques for optical thin films and coatings", in Optical Thin Films and Coatings., USA, Woodhead Publishing Limited, pp. 3-25.

[42] D. Mardare, P. Hones, (1999) “'Optical dispersion analysis of $\mathrm{TiO}_{2}$ thin films based on variable-angle spectroscopic ellipsometry measurements', Materials Science and Engineering, pp. 142-47.

[43] T. Modes, B. Scheffel, C. Metzner, O. Zywitzki, E. Reinhold, (2005) "'Structure and properties of itanium oxide layers deposited by reactive plasma activated electron beam evaporation ', Surface and Coatings Technology, vol. 200, pp. 306-309.

[44] M. Zhang, G. Lin, C. Dong, L. Wen, (2007) “Amorphous TiO2 films with high refractive index deposited by pulsed bias arc ion plating', Surface and Coatings Technology, vol. 201, pp. $7252-7258$. 
[45] Z. Zhao, B. K. Tay, G. Yu, (2004) ' Room-temperature deposition of amorphous titanium dioxide thin film with high refractive index by a filtered cathodic vacuum arc technique', Optical Society of America, vol. 43, pp. 1281-1285.

[46] K. Bouras, G. Schmerber, D. Aureau, H. Rinnert, J. Rehspringer, D. Ihiawakrim, A. Dinia, A. Slaoui, S. Colis, (2019) "Photon management properties of Yb-doped SnO2 nanoparticles synthesized by sol-gel technique", Physical Chemistry Chemical Physics, vol. 21, pp. 2140721417

[47] C.P. Ewels, M. Glerup, (2005) "Nitrogen doping in carbon nanotubes", Journal of Nanoscience and Nanotechnology, vol. 5, pp. 1345-1363.

[48] G. Ciric-Marjanovic, I. Pasti, S. Mentus, (2014) "One-dimensional nitrogen-containing carbon nanostructures", Progress in Materials Science, vol. 69, pp. 61-182.

[49] Y. Zhang, J. Zhang, D.S. Su, (2014) "Substitutional doping of carbon nanotubes with heteroatoms and their chemical applications”, ChemSusChem, vol. 7, pp. 1240-1250.

[50] H. Belkhanchi, Y. Ziat, M. Hammi, C. Laghlimi, A. Moutcine, et al. (2020), "Synthesis of N-CNT/TiO 2 composites thin films: surface analysis and optoelectronic properties", E3S Web of Conferences EDP Sciences, vol. 183, p. 05002.

[51] H. Belkhanchi, Y. Ziat, M. Hammi, C. Laghlimi, A. Moutcine, Anas Benyounes, (2021) "Nitrogen doped carbon nanotubes grafted $\mathrm{TiO}_{2}$ rutile nanofilms: Promising material for dye sensitized solar cell application”, Optik, vol 229, p. 166234

[52] J. C. Manifacier, D. M. Murcia, J. P. Fillard, E. Vicario, (1977) "Optical and electrical properties of $\mathrm{SnO} 2$ thin films in relation to their stoichiometric deviation and their crystalline structure", Thin solid films, vol. 41, pp. 127-135.

[53] R. Swanepoel, (1983) "Determination of the thickness and optical constants of amorphous silicon”, Journal of Physics E: Scientific Instruments, vol. 16, pp. 1214-1222.

[54] K. Lagha-Menouer, (2011) 'Étude et réalisation d'une cellule solaire multicouches du type $\mathrm{Si}$ - $\mathrm{SiO} 2$ - SnO2 - ZnO par APCVD', Mouloud Mammeri. Tizi-Ouzou University, Algeria.

[55] J. Tauc, A. Menth, (1972) “States in the gap”, Non-Crystalline, vol. 8-10, pp. 569-585 
[56] Y. Ziat, A. Abbassi, M. Hammi, A. Ait Raiss, O. El Rhazouani, (2016) "First-principles investigation of the electronic and optical properties of $\mathrm{Al}$-doped $\mathrm{FeS}_{2}$ pyrite for photovoltaic applications”, Opt. Quantum Electron, vol. 48, pp. 511

[57] A. Benyounes, M. Hammi, Y. Ziat, A. Slassi, N. Zahra, (2018), "Fabrication and characterization of novel transparent conducting oxide $\mathrm{N}-\mathrm{CNT}$ doped $\mathrm{ZnO}$ for photovoltaic applications", Appl. Phys. A vol. 90, pp. 124

[58] Z. Zarhri, M. Ángel Avilés Cardos, Y. Ziat, M. Hammi, O. El Rhazouani, J. Cesar Cruz Argüello, D. Avellaneda Avellaneda, (2019), "Synthesis, structural and crystal size effect on the optical properties of sprayed TiO2 thin films: Experiment and DFT TB-mbj”, J. Alloys Compd, vol.819, pp. 153010

[59] M. Hammi , A. Abbassi, (2016),"Comparative study of accurate experimentally determined and calculated band gap of amorphous ZnO layers" Mater. Lett, vol. 166, pp. 206209

[60] B. Pejova, B. Abay, I. Bineva, and F. Bo, "Temperature Dependence of the Band-Gap Energy and Sub-Band-Gap Absorption Tails in Strongly Quantized ZnSe Nanocrystals Deposited as Thin Films," no. 1, pp. 15280-15291, 2010.

[61] J. Tauc, R. Grigorovici, A. Vancu, (1966) ' Optical properties and electronic structure of amorphous germanium', Physica Status Solidi, vol. 15, pp. 627-637.

[62] Abdellah Moustaghfir. Élaboration et caractérisation de couches minces d'oxyde de zinc.Application à la photoprotection du polycarbonate. Matériaux. Université Blaise Pascal Clermont-Ferrand II, 2004. Français. tel-00012168f.

[63] F. Urbach, (1953) "The long-wavelength edge of photographic sensitivity and of the electronic absorption of solids”, American Physical Society, vol. 92, p. 1324.

[64] I. Studenyak, M. Kranj, and M. Kurik, "Urbach Rule in Solid State Physics," j.optics.vol. pp. 76-83, 2014.

[65] E. Burstein, (1954) “Anomalous optical absorption limit in InSb", American Physical Society, vol. 93, pp. 632-633.

[66] T. S. Moss, (1954) "The interpretation of the properties of indium antimonide", Proceedings of the Physical Society, vol. 67, pp. 775-782. 
[67] Wu, K.-H., Cheng, K.-F., Yang, C.-C., Wang, C.-P. and Liu, C.-I. (2015) Thermal and Optical Properties of Epoxy/Siloxane Hybrimer Based on Sol-Gel-Derived Phenyl-Siloxane. Open Journal of Composite Materials, 5, 49-59. 
Figures

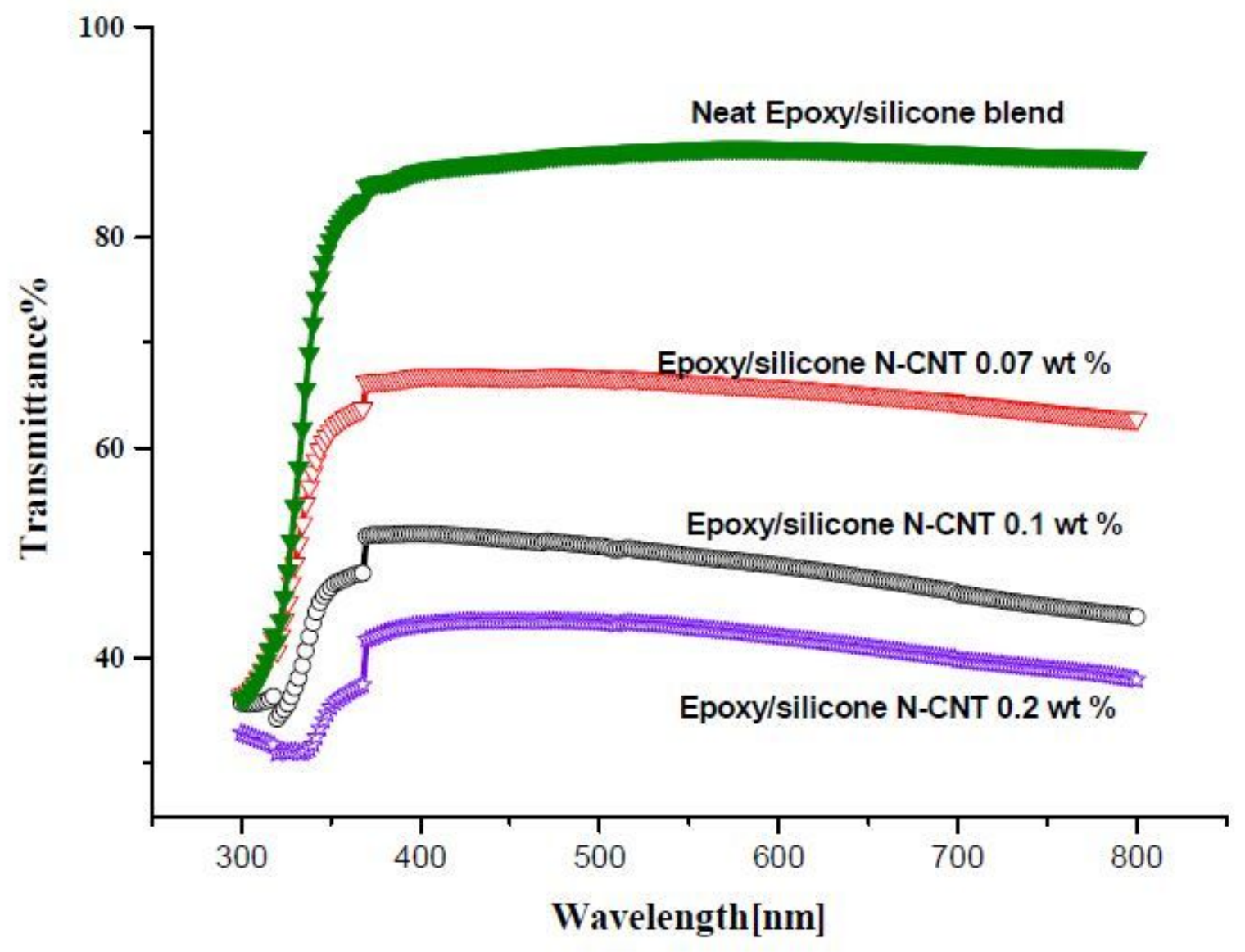

Figure 1

plots of Epoxy/silicone films transmittance as a function of wavelength for different N-CNTs loading rates 


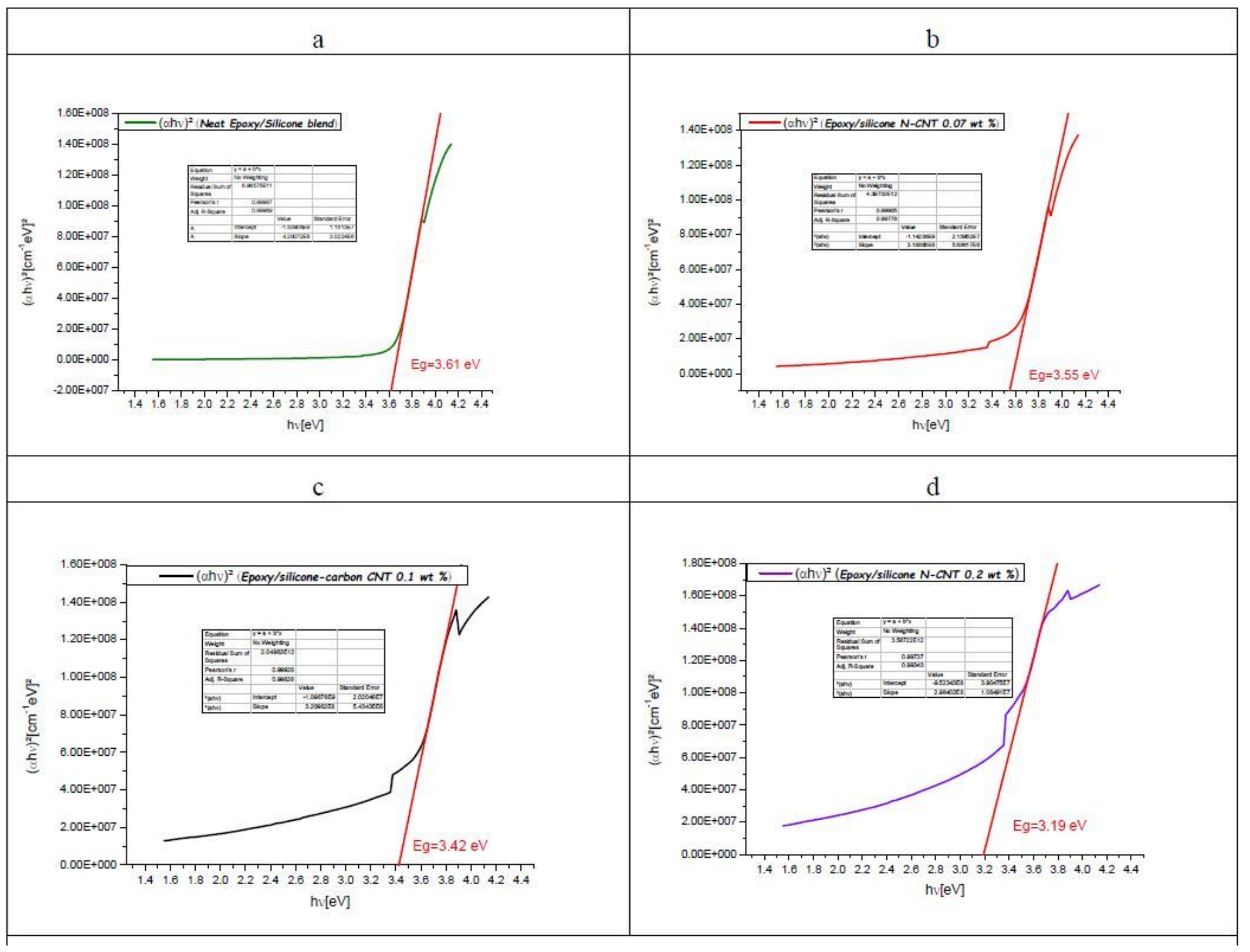

\section{Figure 2}

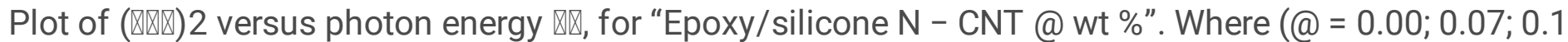
呕 0.2) 


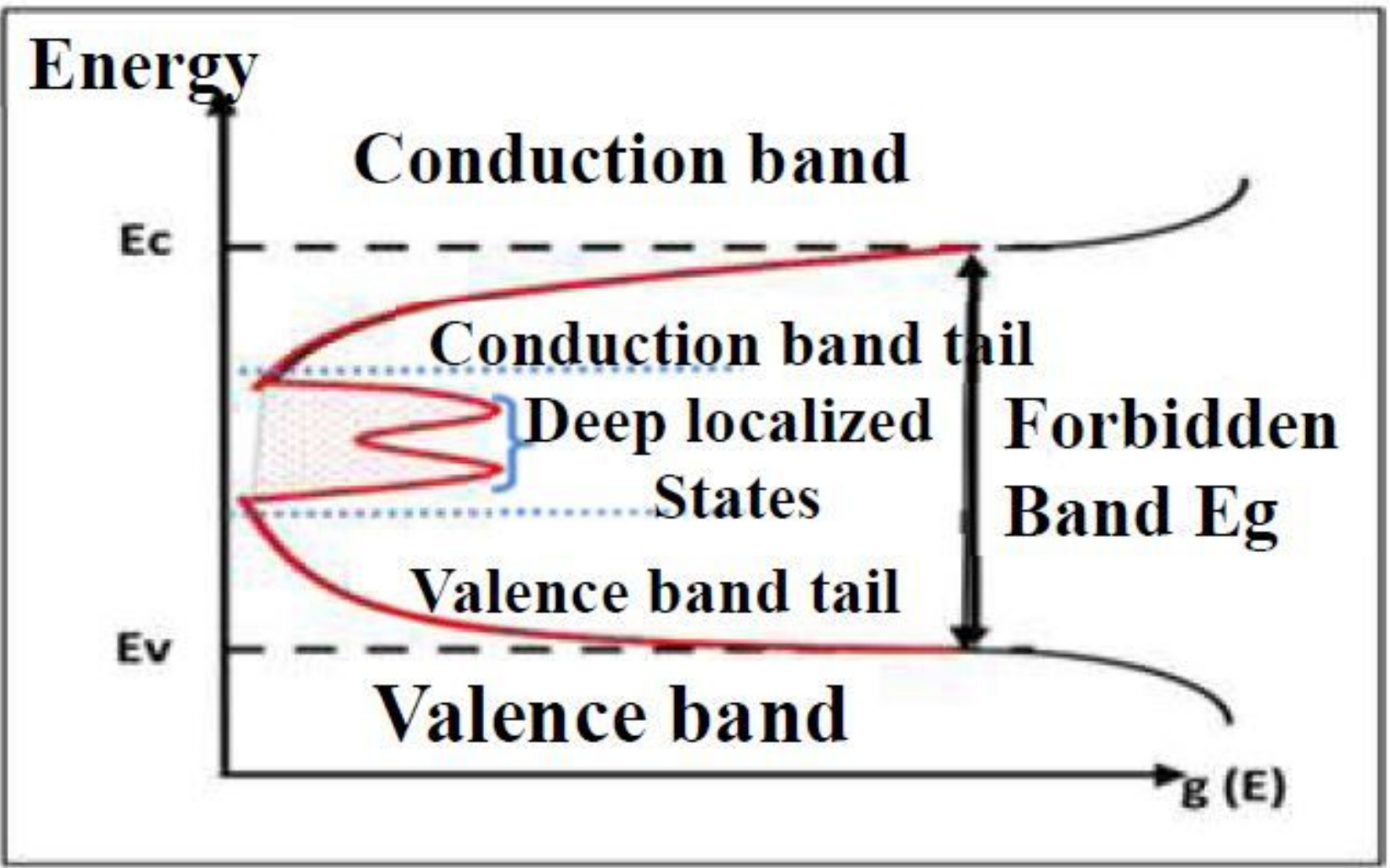

Figure 3

Pseudo-gap of amorphous semiconductors 


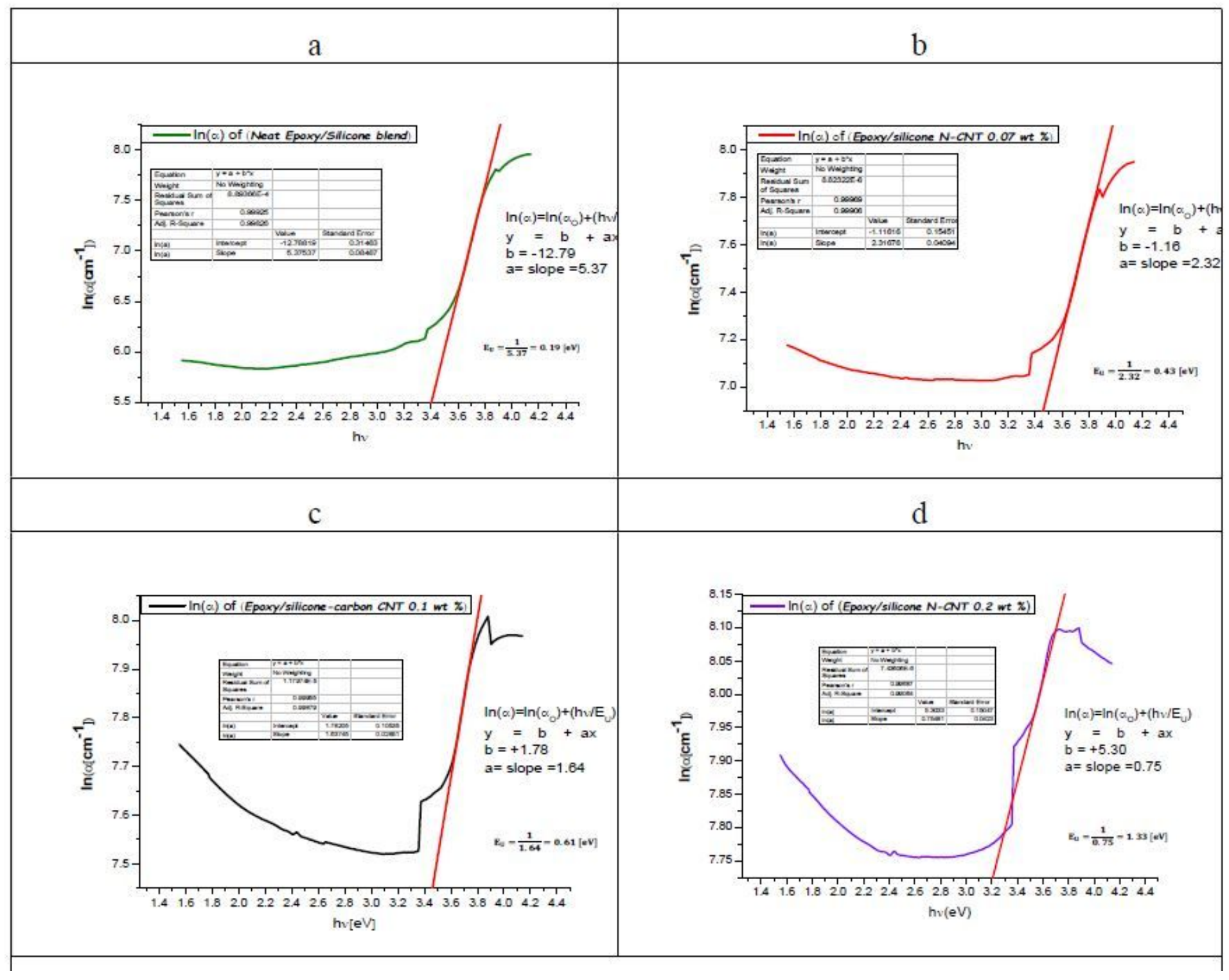

Figure 4

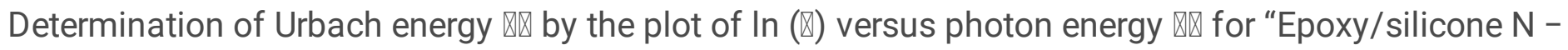
CNT @ wt \%". Where (@= 0.00; 0.07; 0.1 畈 0.2) 


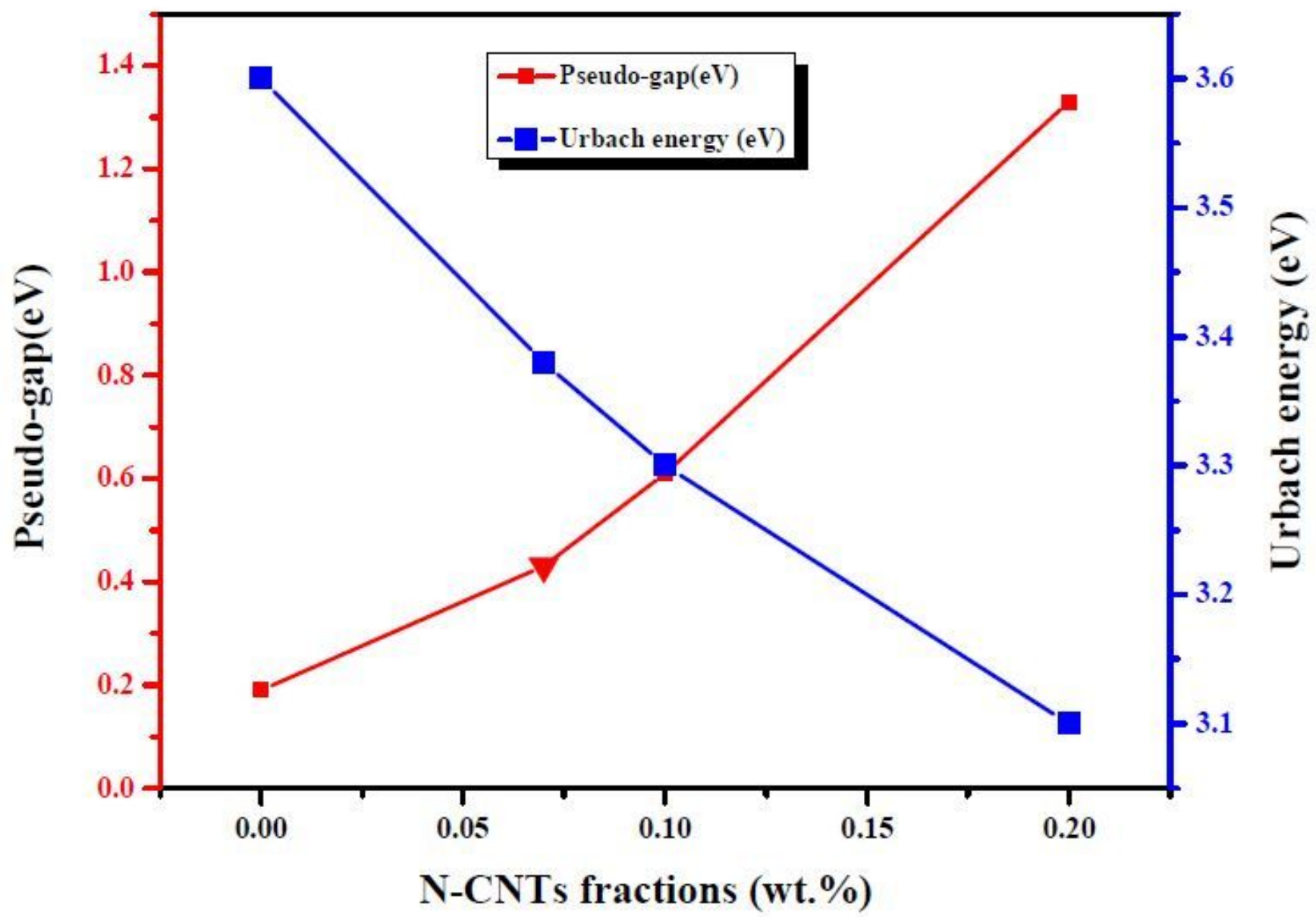

Figure 5

Variation of optical gap and Urbach energy of Epoxy/silicone composite films versus wt\%N-CNT 


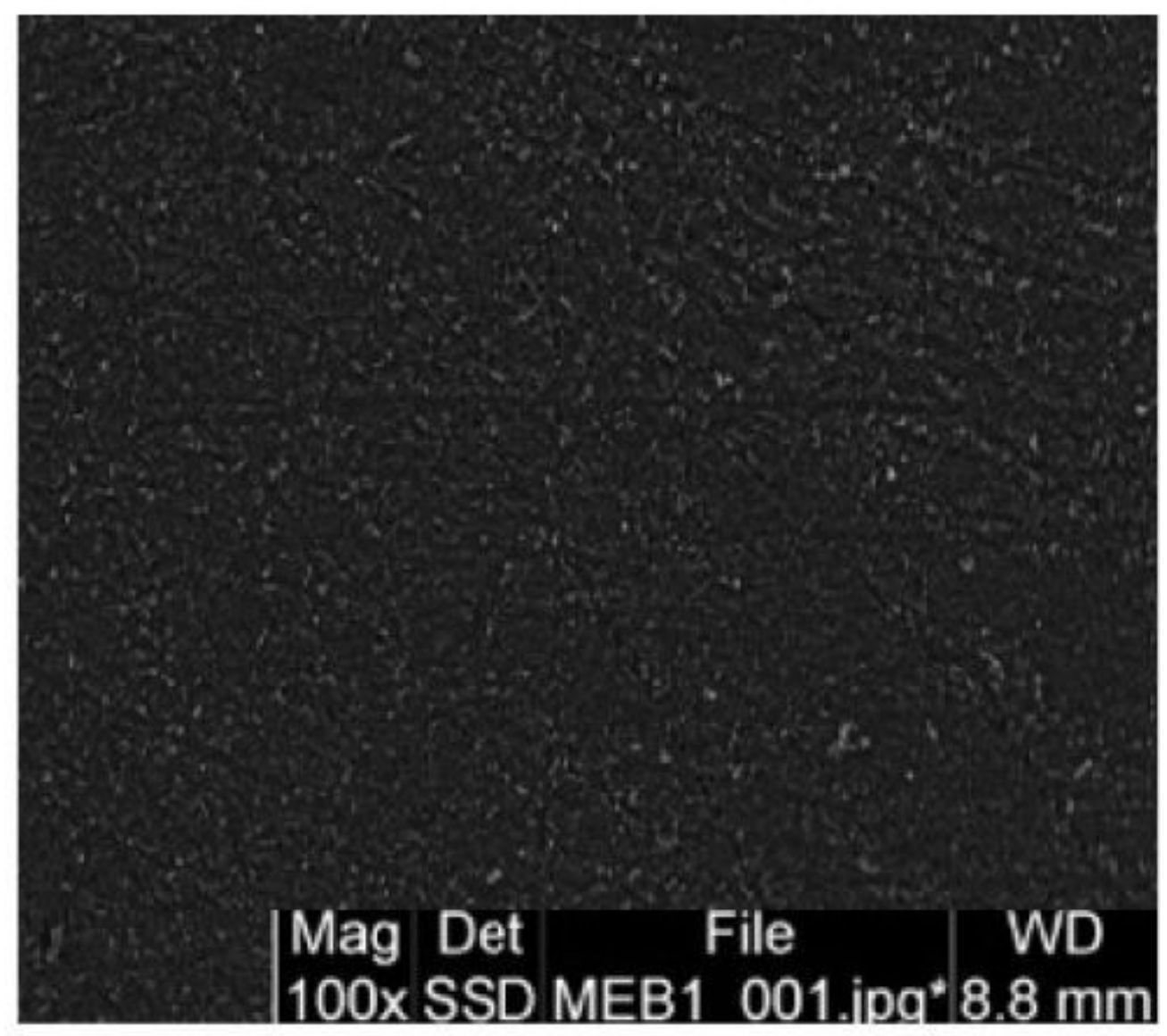

Figure 6

SEM observed the morphology of the thin film surface 